\title{
Functional screening of a cDNA library from the desiccation-tolerant plant Selaginella lepidophylla in yeast mutants identifies trehalose biosynthesis genes of plant and microbial origin
}

\author{
Suzana Pampurova $\cdot$ Katrien Verschooten • \\ Nelson Avonce • Patrick Van Dijck
}

Received: 13 April 2014/ Accepted: 27 July 2014/Published online: 23 September 2014

(C) The Botanical Society of Japan and Springer Japan 2014

\begin{abstract}
Trehalose is a non-reducing disaccharide that accumulates to large quantities in microbial cells, but in plants it is generally present in very low, barely-detectible levels. A notable exception is the desiccation-tolerant plant Selaginella lepidophylla, which accumulates very high levels of trehalose in both the hydrated and dehydrated state. As trehalose is known to protect membranes, proteins, and whole cells against dehydration stress, we have been interested in the characterization of the trehalose biosynthesis enzymes of S. lepidophylla; they could assist in engineering crop plants towards better stress tolerance. We previously isolated and characterized trehalose-6phosphate synthases from Arabidopsis thaliana (desiccation sensitive) and S. lepidophylla (desiccation tolerant) and found that they had similar enzymatic characteristics. In this paper, we describe the isolation and characterization of trehalose-6-phosphate phosphatase from S. lepidophylla and show that its catalytic activities are also similar to those of its homolog in A. thaliana. Screening of an $S$. lepidophylla cDNA library using yeast trehalose biosynthesis mutants resulted in the isolation of a large number of
\end{abstract}

S. Pampurova and K. Verschooten contributed equally to this work.

Electronic supplementary material The online version of this article (doi:10.1007/s10265-014-0663-x) contains supplementary material, which is available to authorized users.

S. Pampurova $\cdot$ K. Verschooten $\cdot$ N. Avonce $\cdot$ P. Van Dijck Department of Molecular Microbiology, VIB, KU Leuven, Leuven, Belgium

S. Pampurova $\cdot$ K. Verschooten $\cdot$ N. Avonce $\cdot$

P. Van Dijck $(\bowtie)$

Laboratory of Molecular Cell Biology, KU Leuven, Kasteelpark

Arenberg 31 bus 2438, 3001 Leuven, Belgium

e-mail: patrick.vandijck@mmbio.vib-kuleuven.be trehalose biosynthesis genes that were of microbial rather than plant origin. Thus, we suggest that the high trehalose levels observed in S. lepidophylla are not the product of the plant but that of endophytes, which are known to be present in this plant. Additionally, the high trehalose levels in $S$. lepidophylla are unlikely to account for its desiccation tolerance, because its drought-stress-sensitive relative, $S$. moellendorffi, also accumulated high levels of trehalose.

Keywords Desiccation tolerance $\cdot$ Selaginella lepidophylla · TPS · TPP · Trehalose

\section{Introduction}

Trehalose is a non-reducing disaccharide ( $\alpha$-D-glucopyranosyl-(1 $\rightarrow 1)$ - $\alpha$-D-glucopyranoside) present in bacteria, yeast, fungi, invertebrates, and desiccation-tolerant plants. In these different organisms, trehalose functions as a reserve carbohydrate as well as an important stress-protecting molecule (Elbein et al. 2003). The hydrolysis of trehalose is a major event during fungal spore germination (Thevelein 1984) and insect flight (Becker et al. 1996), where trehalose presumably supplies glucose as a carbon and energy source. In mycobacteria and corynebacteria, trehalose is also an important structural component of the cell wall (Lederer 1976). Finally, trehalose, trehalose 6-phosphate (T6P; the intermediate molecule during trehalose biosynthesis), or the enzymes involved in its biosynthesis have also been shown to act as regulatory molecules, e.g., by controlling the influx of glucose into glycolysis in yeast cells (Bonini et al. 2003; Hohmann et al. 1996).

Desiccation-tolerant organisms are able to lose 80-95\% of their water content and stay dormant in the dehydrated state until water becomes available (Crowe et al. 1992). 
A common characteristic in most of these organisms is the rapid increase in compatible solutes, such as trehalose, during dehydration. High trehalose contents have been measured during desiccation in some 'resurrection' plants, yeast and bacterial cells, fungal spores, and also in microscopic animals such as nematodes, rotifers and, tardigrades (Hengherr et al. 2008; Oliver et al. 2000). In the course of desiccation, trehalose contributes to membrane stability by preventing the lipid phase transition and fusion of drying vesicles (Crowe 2007). Furthermore, the accumulation of trehalose in response to stress in Archaebacteria suggests that the protective role of trehalose during cell dehydration might be an ancient adaptation that is evolutionarily preserved in desiccation-tolerant plants (Zaparty et al. 2013). Among vascular plants, high amounts of trehalose are detected in only a few desiccation-tolerant plants, such as Myrothamnus flabellifolius, Sporobolus atrovirens, and Selaginella lepidophylla (Müller et al. 1995).

Selaginella lepidophylla is a desiccation-tolerant plant from the Chihuahuan desert of North America. This lycophyte is able to lose $80-95 \%$ of its protoplasmic water during a dry period and revive when water becomes available again (Yobi et al. 2012). During the dehydrationhydration cycles, the stems of S. lepidophylla curl and uncurl. Ultrastructural and biochemical analyses of the microphyll behavior during rehydration uncurling showed that the cellular and basal enzymatic integrity of the desiccated microphylls was conserved (Adams et al. 1990; Bergtrom et al. 1982; Yobi et al. 2013). Exceptionally for plants, the trehalose content in S. lepidophylla exceeds those of sucrose and glucose; however, in its desiccationsensitive relative Selaginella moellendorffi, even higher levels of trehalose were detected (Yobi et al. 2012, 2013). We recently summarized the characteristics of $S$. lepidophylla that may be involved in its extreme drought-stress tolerance (Pampurova and Van Dijck 2014).

Because of the very low trehalose content in most vascular plants, they were thought to have lost the capacity to produce this molecule and that it was replaced by sucrose. However, most or all desiccation-intolerant vascular plants, such as Arabidopsis thaliana and Oryza sativa, harbor large trehalose-biosynthetic gene families in their genomes (Avonce et al. 2010; Leyman et al. 2001; Lunn 2007). In plants, trehalose biosynthesis involves a two-step pathway catalyzed by T6P synthase (TPS; EC 2.4.1.15) and T6P phosphatase (TPP; EC 3.1.3.12) (Avonce et al. 2006). In the first step, TPS catalyzes the transfer of glucose from UDP-glucose to glucose 6-phosphate forming T6P and UDP, while in the second step TPP dephosphorylates T6P to trehalose and inorganic phosphate (Elbein et al. 2003). Trehalose is catabolized by trehalase (EC 3.2.1.28) into two glucose moieties (Avonce et al. 2006). In the model plant A. thaliana, there are 11 genes encoding TPS- or
TPS-like proteins, 10 encoding TPPs, and one encoding trehalase (Leyman et al. 2001).

Given the high trehalose content in S. lepidophylla, the characterization of its trehalose biosynthetic genes might provide insights into the evolutionary preservation of trehalose in a desiccation-tolerant plant. Until now, only one TPS-encoding gene (designated SITPSI) has been reported from S. lepidophylla (Márquez-Escalante et al. 2006; Valenzuela-Soto et al. 2004; Van Dijck et al. 2002). Similar to AtTPS1, this SITPS1 is able to complement a yeast tps1 14 mutant growing on glucose, but only when its inhibitory $N$-terminal domain is removed (Van Dijck et al. 2002). The removal of this domain results in very high enzymatic activity upon expression in yeast (Van Dijck et al. 2002). One hypothesis that may support high trehalose levels in S. lepidophylla is that in this plant the $N$ terminal domain may be inhibited by a protein or metabolite or removed by a specific protease, resulting in high enzymatic activity. To investigate this possibility, we generated an S. lepidophylla cDNA library in a yeast expression vector. A large number of screenings in yeast resulted in the identification of many TPS-encoding genes that showed more homology with fungal TPS than with plant TPSs. Because S. lepidophylla harbors many endophytes (Brighigna et al. 2002) and is unable to regenerate from spores without them, i.e., when grown in sterile conditions (personal communication, G. Iturriaga), we here suggest that the high trehalose levels present in S. lepidophylla originate from the endophytes and are required for normal growth of S. lepidophylla.

\section{Materials and methods}

\section{Plant material}

Desiccated S. lepidophylla plants were obtained from Prof. G. Iturriaga (Centro de Investigación en BiotecnologíaUAEM, Morelos, Mexico) and from the companies Floréac (Lochristi, Belgium) and Livo B.V. (Overijssel, The Netherlands). To construct the cDNA library, plant samples were taken at four different time points during a rehydration/dehydration cycle. Selaginella lepidophylla plants used for real-time quantitative reverse transcription PCR (RT-qPCR) analysis were completely hydrated (4 days hydration after the initial rehydration/dehydration cycle) and completely dehydrated (3 days dehydrated after the initial rehydration/dehydration cycle).

\section{Selaginella lepidophylla cDNA library construction}

RNA samples were collected from fully-desiccated, hydrated (24 h after watering), partly-dried plants $(8 \mathrm{~h}$ 
drying), and completely-dried plants ( $24 \mathrm{~h}$ drying). RNA extraction was performed as previously described (Valenzuela-Avendano et al. 2005). Complementary DNA was generated using the cDNA library construction kit (Invitrogen, Carlsbad, CA, USA), cloned in the Gateway donor vector $\mathrm{pDONR} 222$, and transferred to the yeast expression vector pVV214 (Van Mullem et al. 2003). The resulting cDNA library was composed of $1.019 \times 10^{11}$ colony forming units $\mathrm{ml}^{-1}$ with an average cDNA insert size of $1.16 \mathrm{~kb}$.

Isolation of proteins interacting with the $N$-terminus of SlTPS1

Expression of SlTPS1 in a yeast tps1 14 mutant does not restore growth on glucose (Van Dijck et al. 2002). However, expression of a construct in which the first 300 nucleotides (100 amino acids) of SITPS1 were removed resulted in the production of a protein with high enzymatic activity and was able to restore the mutant's growth on glucose. To identify proteins that might interact with the $N$ terminus and remove its inhibitory activity on the catalytic domain, we transformed the S. lepidophylla cDNA library into a Saccharomyces cerevisiae strain (Gietz et al. 1995) expressing the full-length SITPS1 and selected transformants that could grow on glucose. Plasmids from positive clones were isolated, amplified in E. coli, and retransformed into the same yeast strain for confirmation. The inserts of the positive clones were sequenced.

Isolation of TPP and TPS genes from S. lepidophylla cDNA library

To isolate TPP and TPS genes, we transformed the cDNA library into yeast $t p s 1 \Delta$ or $t p s 2 \Delta$ strains, which lack TPS or TPP activity, respectively. Complemented transformants that could grow on glucose (tps1 4 ) or at $38{ }^{\circ} \mathrm{C}$ (tps $\left.2 \Delta\right)$ were retested in a spot assay. For the spot assays, overnight liquid cultures were adjusted to an optical density at $600 \mathrm{~nm}\left(\mathrm{OD}_{600}\right)=0.1$, diluted tenfold, and spotted $(5 \mu \mathrm{L})$ on synthetic solid medium without uracil and with glucose or galactose as carbon source. Transformants in the tps $1 \Delta$ background were selected for growth on glucose, and transformants in the tps $2 \Delta$ background were selected for growth at $38{ }^{\circ} \mathrm{C}$. Plasmids from positive clones were isolated, amplified in E. coli, and retransformed into the same yeast strain for confirmation. The inserts of the positive clones were sequenced.

In an alternative approach to isolate these genes, we used the degenerate-oligonucleotide PCR approach. Based on sequences obtained from searches of the S. lepidophylla EST library (Iturriaga et al. 2006) and homologous TPS and TPP genes from other species, degenerate primers (see
Table S1) were designed and combined with primers specific to the AttB-sites on the pVV214 vector. After obtaining specific cDNA fragments, a second set of primers was designed to obtain the complete cDNA sequence. The following PCR program was used: initial denaturation at $95{ }^{\circ} \mathrm{C}$ for $5 \mathrm{~min}$, five cycles of $\left(95^{\circ} \mathrm{C}\right.$ for $1 \mathrm{~min}, 30^{\circ} \mathrm{C}$ for $1 \mathrm{~min}, 72{ }^{\circ} \mathrm{C}$ for $\left.2 \mathrm{~min}\right), 30$ cycles of $\left(95^{\circ} \mathrm{C}\right.$ for $1 \mathrm{~min}$, $55{ }^{\circ} \mathrm{C}$ for $1 \mathrm{~min}, 72{ }^{\circ} \mathrm{C}$ for $2 \mathrm{~min}$ ), and final extension step at $72{ }^{\circ} \mathrm{C}$ for $7 \mathrm{~min}$. To obtain the full cDNA sequence with the specific primers, after initial denaturation for $5 \mathrm{~min}$ at $95{ }^{\circ} \mathrm{C}$, the reaction was as follows: 35 cycles $\left(95^{\circ} \mathrm{C}\right.$ for $40 \mathrm{~s}, 65^{\circ} \mathrm{C}$ for $1 \mathrm{~min}, 72{ }^{\circ} \mathrm{C}$ for $1 \mathrm{~min}$ ) and final extension at $72{ }^{\circ} \mathrm{C}$ for $7 \mathrm{~min}$.

\section{Phylogenetic analysis}

The sequences used for the phylogenetic reconstruction of the TPP gene family were collected using the PLAZA 1.0 platform (Proost et al. 2009) as previously described (Avonce et al. 2010). The gene families from Physcomitrella patens, A. thaliana, and $S$. moellendorffii were included in the analysis (supplementary Table 2). Multiple sequence alignment of the deduced protein sequences was performed with Clustal Omega (Sievers et al. 2011), and ClustalW2 (Larkin et al. 2007) was used to calculate a distance matrix with the neighbor-joining algorithm. The estimated phylogenetic trees were drawn with NJplot (Perrière and Gouy 1996).

\section{Growth conditions, yeast strains and transformation}

Yeast cells were grown in synthetic growth medium $(1.7 \mathrm{~g}$ Bacto-yeast nitrogen base without amino acids ( $\mathrm{pH}$ 6.0), $5 \mathrm{~g}$ ammonium sulfate; supplemented with $50 \mathrm{mg}$ adenine, $100 \mathrm{mg}$ histidine, $250 \mathrm{mg}$ leucine, $100 \mathrm{mg}$ tryptophan, and $50 \mathrm{mg}$ uracil in $1 \mathrm{~L}$ ) and $2 \%$ galactose (SGal) or $2 \%$ glucose (SGlc). The yeast strains were: wild-type (WT), W303-1A (Mata leu2-3, 112 ura3-1 trp1-1 his3-11, 15 ade2-1 can1-100 GAL SUC2) (Thomas and Rothstein 1989); tps1 1 , YSH290 (W303-1A, tps1 $\triangle:: T R P 1)$ (Hohmann et al. 1993); and tps2A, YSH488 and YSH587 (W303-1A, tps2 $\triangle:: L E U 2$ ) (Neves et al. 1995). Shuttle vectors pSAL4 (Zentella et al. 1999) and pYX212 (Novagen) were used to express the genes of interest in yeast. Yeast transformation was performed according to Elble (1992), and transformants were selected on plates containing minimal medium without uracil.

Trehalose measurements

Trehalose was measured as previously described using Humicola sp. trehalase and glucose oxidase/peroxidase assays (Zentella et al. 1999). 
TPP activity

TPP activity was determined as previously described (De Virgilio et al. 1993; Zentella et al. 1999). Protein concentrations were measured with the Bradford method (Bradford 1976). Enzyme activity is expressed as nanokatals per gram of protein (nkat $\mathrm{g}$ protein ${ }^{-1}$ ).

\section{qRT-PCR analysis}

Gene expression was tested with RT-qPCR. RNA was extracted according to Valenzuela-Avendano et al. (2005), and cDNA was prepared from $2 \mu \mathrm{g}$ of total RNA using a commercial cDNA synthesis kit (Invitrogen) before analysis on an ABI PRISM 7000 thermocycler using Platinum SYBR Green qPCR SuperMix UDG (Invitrogen) according to manufacturer's instructions. All reactions were done in triplicate. Relative expression levels of target genes were quantified with specific primer sets (Table S1), and $26 \mathrm{~S}$ $r R N A$ gene expression was used as an internal standard. To calculate the transcript quantity relative to the hydrated state, the $2^{\Delta \Delta C_{\mathrm{t}}}$ method was used. Statistical significance was calculated using Student's $t$ test.

\section{Results}

Initial screening of S. lepidophylla cDNA library for TPS and TPP genes

We used $S$. cerevisiae tps $1 \Delta$ and tps $2 \Delta$ strains to isolate TPS or TPP genes from the desert resurrection plant $S$. lepidophylla. A total of 30,000 transformants was screened for growth on glucose (tps $1 \Delta$ complementation) and at $38{ }^{\circ} \mathrm{C}$ (tps $2 \Delta$ complementation). Plasmid DNA from positive transformants was isolated and retested. Interestingly, screening for genes that suppressed the glucose growth defect of the tps $1 \Delta$ strain led to the identification of several genes with higher sequence similarities to fungal TPS than to plant TPS proteins (Table 1). Furthermore, the positive clones that allowed growth at $38^{\circ} \mathrm{C}$ of the tps $2 \Delta$ strain harbored genes encoding stress proteins, such as LEA proteins and dehydrins, instead of the expected TPP genes.

Isolation of active microbial TPS genes from the S. lepidophylla cDNA library

According to Adams et al. (1990) the content of trehalose in S. lepidophylla is much higher than in other plants. We have previously shown that an $N$-terminal truncation of SITPS1 (or AtTPS1) results in a much higher enzymatic activity and very good complementation of the yeast tps $1 \Delta$ mutant (Van Dijck et al. 2002). One possibility for the high trehalose
Table 1 Genes isolated by screening for Selaginella lepidophylla proteins that can complement the growth defects of the yeast tps $1 \Delta$ (glucose tolerance) or the yeast tps $2 \Delta$ mutant (growth at high temperature) mutants

\begin{tabular}{|c|c|c|c|c|}
\hline $\begin{array}{l}\text { Growth } \\
\text { conditions }\end{array}$ & Strain & Gene & Species & Kingdom \\
\hline Glucose & $\operatorname{tps} 1 \Delta$ & TPS & $\begin{array}{l}\text { Coniosporium } \\
\text { apollinis }^{\mathrm{a}}\end{array}$ & Fungi \\
\hline Glucose & $\operatorname{tps} 1 \Delta$ & TPS & $\begin{array}{l}\text { Polysphondylium } \\
\text { pallidum }^{\mathrm{a}}\end{array}$ & Amoebozoa \\
\hline Glucose & $\operatorname{tps} 1 \Delta$ & TPS & $\begin{array}{l}\text { Leptosphaeria } \\
\text { maculans }^{\mathrm{a}}\end{array}$ & Fungi \\
\hline Glucose & $\operatorname{tps} 1 \Delta$ & TPS & $\begin{array}{l}\text { Exophiala } \\
\text { dermatitidis }^{\mathrm{a}}\end{array}$ & Fungi \\
\hline $38{ }^{\circ} \mathrm{C}$ & $\operatorname{tps} 2 \Delta$ & DHN & $\begin{array}{l}\text { Selaginella } \\
\quad \text { lepidophylla }^{\mathrm{b}}\end{array}$ & Plantae \\
\hline $38^{\circ} \mathrm{C}$ & $\operatorname{tps} 2 \Delta$ & LEA & $\begin{array}{l}\text { Selaginella } \\
\quad \text { lepidophylla }\end{array}$ & Plantae \\
\hline $38{ }^{\circ} \mathrm{C}$ & $\operatorname{tps} 2 \Delta$ & ELIP & $\begin{array}{l}\text { Selaginella } \\
\quad \text { lepidophylla }^{\mathrm{b}}\end{array}$ & Plantae \\
\hline $38^{\circ} \mathrm{C}$ & $\operatorname{tps} 2 \Delta$ & GST & $\begin{array}{l}\text { Selaginella } \\
\quad \text { lepidophylla }\end{array}$ & Plantae \\
\hline
\end{tabular}

TPS T6P synthase, $D H N$ dehydrin, $L E A$ late embryogenesis abundant protein, ELIP early light inducible protein, GST glutathione- $S$ transferase

a The closest homologs to the isolated TPS genes are from the indicated species

b The isolated genes are complete matches with already-identified genes from S. lepidophylla

content in S. lepidophylla is that the $N$-terminal domain is non-functional or removed in this plant, possibly by being bound or cut by another protein. To isolate such proteins, we used the $S$. lepidophylla cDNA library to screen a tps $1 \triangle$ yeast strain expressing the full-length SITPS1 gene for transformants that could grow on glucose. Such transformants may express a protein that releases high TPS catalytic activity.

One hundred and forty colonies that were obtained grew on glucose. The positive plasmids were re-tested by retransformation in the tps $1 \Delta$ strain expressing the fulllength SITPS1 gene. As in the first screen, the positive clones contained sequences with the closest similarity to TPS enzymes of microbial origin, indicating that the glucose growth complementation was a result of expressing heterologous TPS genes. The two most frequently isolated TPS genes, glu13 and glu15, had highest homology to TPS genes from the rock-inhabiting fungus Coniosporium apollinis (81.68\% amino acid identity) and the amoebozoan Polysphondylium pallidum (61.05\%), respectively (Fig. 1a). The microbial genes glu 13 and glu 15 encode for active TPS enzymes, because their expression could complement the growth defect of the yeast tps $1 \Delta$ mutant on glucose, even in the absence of the SITPS1 gene (Fig. 1b). As in the first screening, no plant TPS1 homologs were isolated. 
Fig. 1 Screening for Selaginella lepidophylla trehalose biosynthetic genes resulted in the isolation of a number of microbial TPS genes. a Phylogenetic analysis of the isolated TPS genes (see Table S2 for information on the genes used in this analysis). The most frequently-isolated transformants, glu15 and glu13, were most homologous with TPS genes from Amoebozoa and Fungi, respectively. b The microbial glu15 and glu13 genes are active TPS genes. Expression of glu15 and glu13 under the control of a yeast constitutive promoter (PGK promoter) results in complementation of the yeast tps1 14 mutant for growth on glucose. The yeast ScTPS1 gene under control of the CUP1 promoter, which is less active than the $P G K$ promoter, was used as a control a

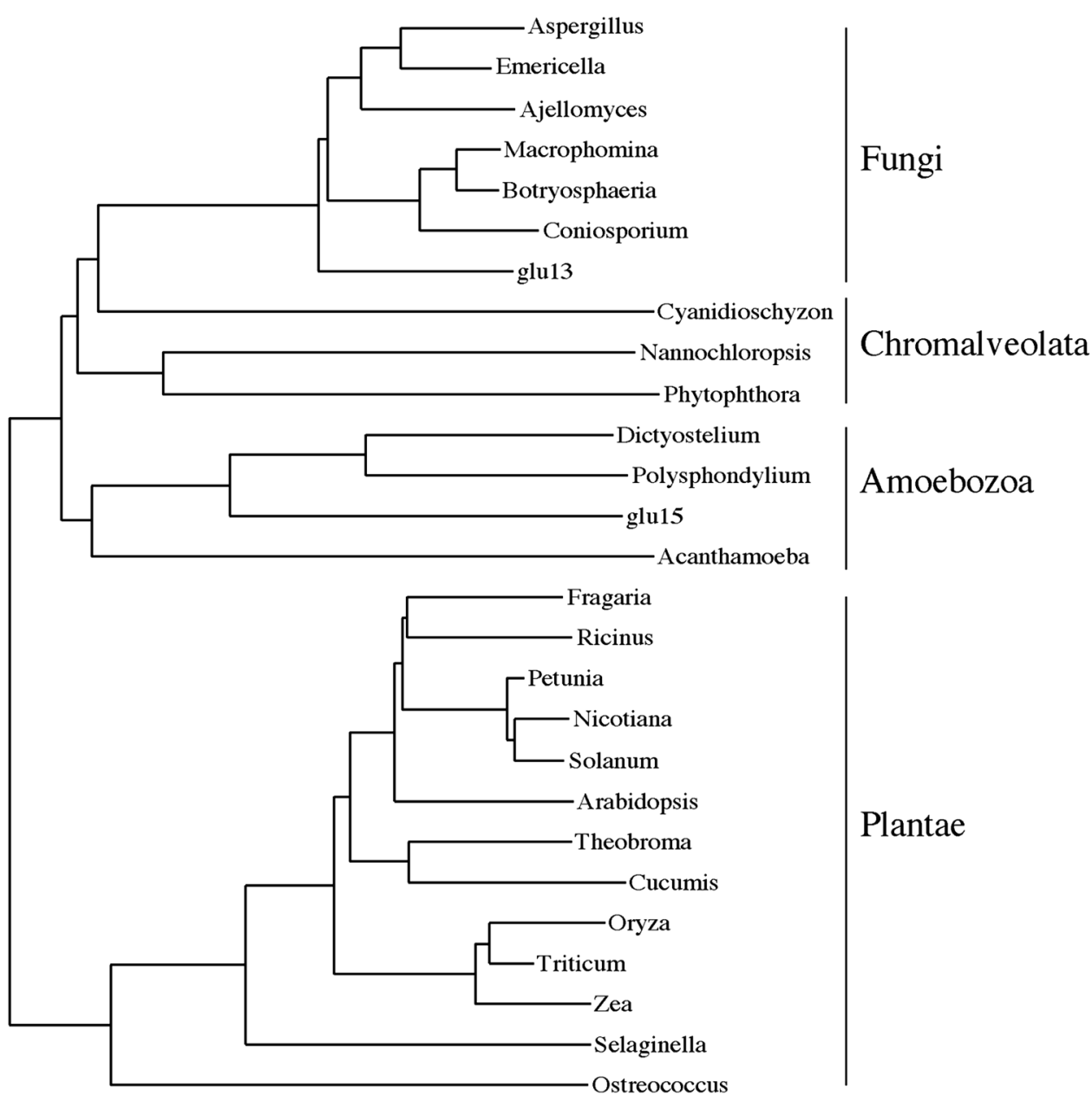

b

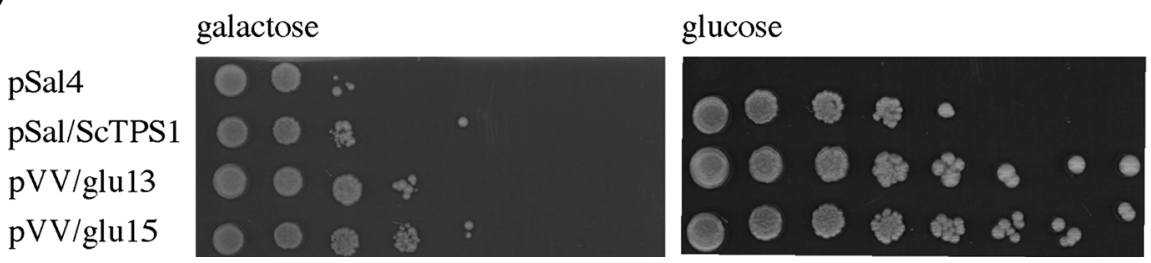

Isolation and characterization of S. lepidophylla TPPs

SITPP genes were not isolated during the S. lepidophylla library screenings, so a degenerate-oligonucleotide-based PCR approach was used. Degenerate oligonucleotides were designed according to sequences from the available $S$. lepidophylla EST library and from TPP genes from other plant species. Based on the sequences of the primary PCR products, a second set of primers was designed and used in combination with primers annealing to the vector sequence to amplify the complete cDNA inserts. Three SITPP genes, named SITPPA, SITPPB, and SITPPC, were isolated. To phylogenetically characterize them, the TPP gene families from three selected species were obtained from PLAZA 1.0 (Proost et al. 2009): Physcomitrella patens had eight TPP genes (PP00032G01010, PP00046G00150, PP00047G00570, PP00056G01260, PP00141G00660, PP00201G00540, PP00227G00210, and PP00333G00270), S. moellendorffii had two (SM00030G00440 and SM00032G01340), and A. thaliana had 10 (AT1G22210, AT1G35910, AT1G78090, AT2G22190, AT4G12430, AT4G22590, AT4G39770, AT5G10100, AT5G51460, and $A T 5 G 65140)$. According to our phylogenetic analysis, SITPPA and SITPPC were orthologous SM00032G01340 and SM00030G00440, respectively, inferring a common 
Fig. 2 Phylogenetic analysis and functional characterization of Selaginella lepidophylla TPP genes. a Phylogenetic analysis of SITPP and TPP genes from Arabidopsis thaliana,

Physcomitrella patens, and Selaginella moellendorffii (see Table S2 for information on the genes used in this analysis). SITPPA and SITPPC are clear orthologs of the two $S$. moellendorffii genes, while. SITPPB did not seem to have an ortholog in this species. b SITPPA and SITPPB are active $T P P$ genes. Expression of SITPPA and SITPPB in a yeast tps $2 \triangle$ strain restores growth at $38^{\circ} \mathrm{C}$, whereas strains transformed with empty plasmids do not grow at this temperature. The $A$. thaliana $T P P B$ gene was used as a control a
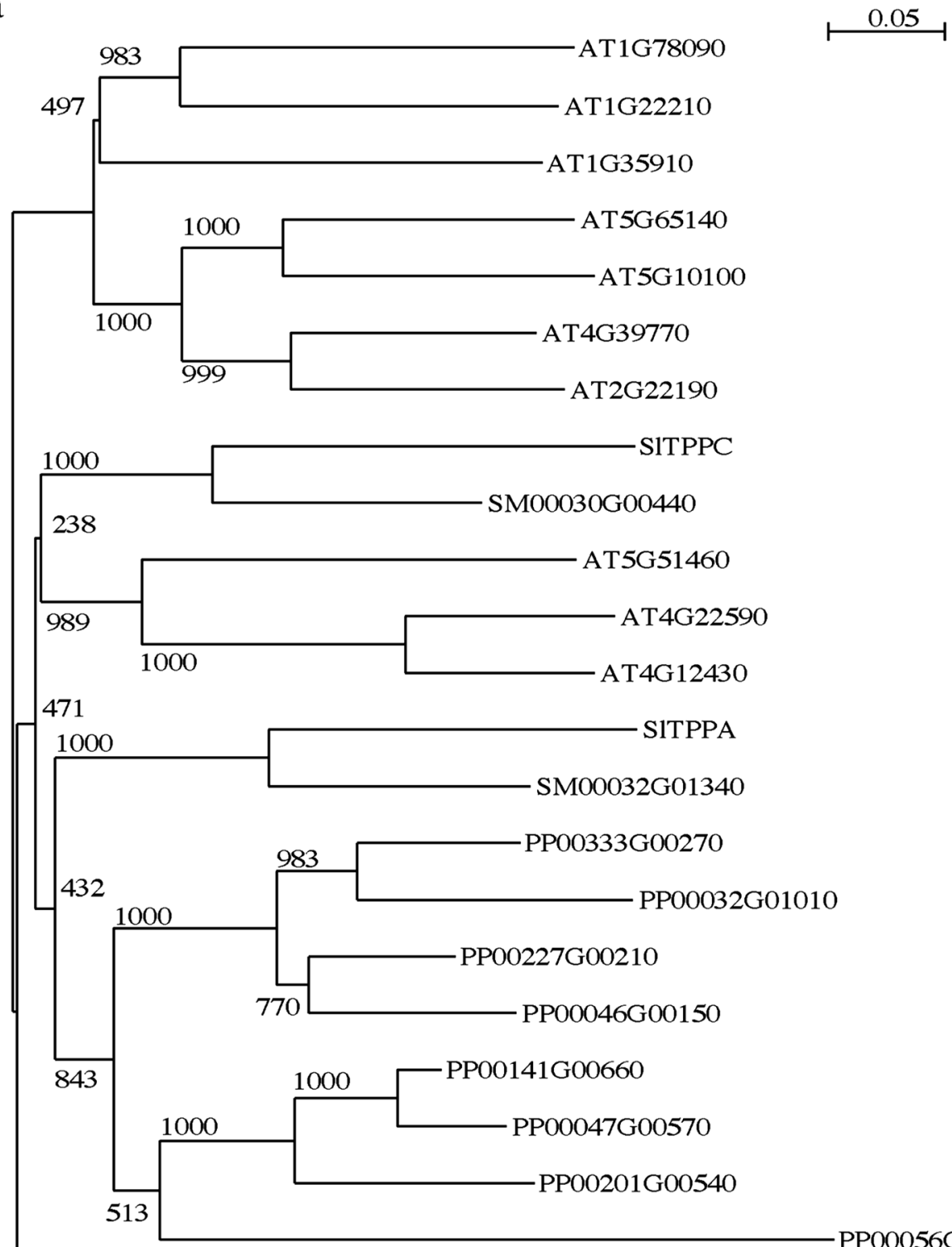

PP00056G01260

b

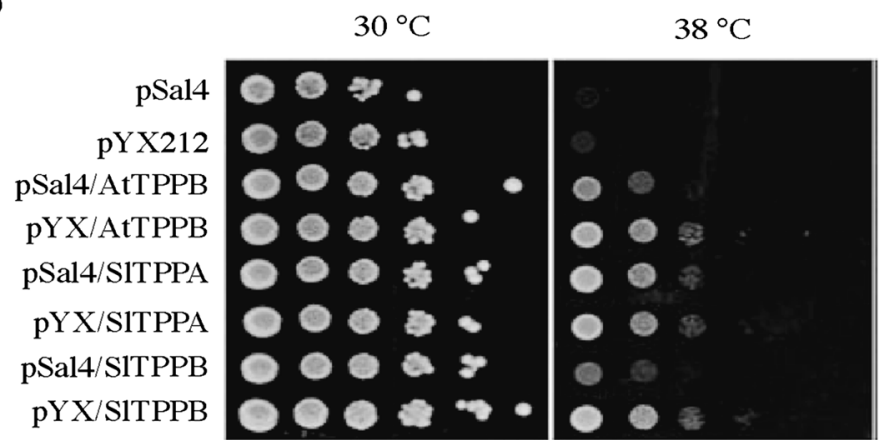

ancestor gene prior to the speciation event separating $S$. moellendorffii and S. lepidophylla. The SITPPB gene did not have an ortholog in $S$. moellendorffi (Fig. 2a).
To investigate the functional activity of the SITPPA (pI $5.36,45.87 \mathrm{kDa}$ ) and SITPPB (pI 5.65, $34.39 \mathrm{kDa}$ ) proteins, the genes were cloned into pSal 4 and pYX212 vectors 
Table 2 Trehalose levels and TPP enzymatic activity of wild type and tps $2 \triangle$ yeast strains expressing the Selaginella lepidophylla TPPA or $T P P B$ gene

\begin{tabular}{|c|c|c|c|}
\hline Strain & Plasmid & $\begin{array}{l}\text { Trehalose } \\
\left(\mu \mathrm{mol} \text { g wet weight }{ }^{-1}\right)\end{array}$ & $\begin{array}{l}\text { TPP activity } \\
\left(\text { nkat }^{g} \text { protein }^{-1}\right)\end{array}$ \\
\hline $\begin{array}{l}\text { Wild } \\
\text { type }\end{array}$ & pYX212 & $99.3 \pm 1.1$ & 799.6 \\
\hline $\operatorname{tps} 24$ & pYX212 & $38 \pm 4.4$ & 0 \\
\hline tps $2 \Delta$ & $\begin{array}{r}\text { pYX212/ } \\
\text { SITPPA }\end{array}$ & $52 \pm 4.6$ & 3.2 \\
\hline $\operatorname{tps} 2 \Delta$ & $\begin{array}{r}\text { pYX212/ } \\
\text { SITPPB }\end{array}$ & $61.3 \pm 3.8$ & 13.6 \\
\hline $\operatorname{tps} 24$ & $\begin{array}{l}\text { pYX212/ } \\
\text { AtTPPB }\end{array}$ & $57.7 \pm 5.1$ & 0 \\
\hline
\end{tabular}

pYX212 empty vector, SITPPA and SITPPB S. lepidophylla TPPs, AtTPPB Arabidopsis thaliana TPPB

and introduced into yeast. Complementation assays showed that SITPPA and SITPPB were active TPPs, able to complement the growth of a yeast $t p s 2 \Delta$ at $38{ }^{\circ} \mathrm{C}$ (Fig. 2b). The trehalose measurements indicated a subtle increase in trehalose content for SITPPA and SITPPB, with $52 \pm 4.6$ and $61.3 \pm 3.8 \mu \mathrm{mol} \mathrm{g}^{-1}$, respectively, compared with $38 \pm$ 4.3 and $99.3 \pm 1.1 \mu \mathrm{mol} \mathrm{g}{ }^{-1}$ measured in the tps $2 \Delta$ and the WT strains, respectively. This correlated with a measurable level of TPP activity, 3.2 and 13.6 nkat $\mathrm{g}_{\text {protein }}{ }^{-1}$ measured in $S I T P P A$ and $S I T P P B$ transformants, respectively, compared with the control tps $2 \triangle$ strain, in which no TPP enzymatic activity could be measured. Compared with the 799.6 nkat g protein $^{-1}$ measured in the WT strain, the enzymatic activities obtained with the S. lepidophylla TPP genes were low (Table 2).

\section{Isolation of an S. lepidophylla class II TPS gene}

Apart from the active TPS and TPP enzymes (SITPS1 and SITPPA, SITPPB, and SITPPC in S. lepidophylla), all plants also have genes that encode for so-called class II TPS enzymes. They are very similar to the class I active TPS enzymes but lack the $N$-terminal extension, and some crucial amino acids in the catalytic domains are not conserved. Most species have more class II than class I enzymes (e.g., A. thaliana has four and seven, respectively); only in the primitive alga Ostreococcus tauri is there an equal number (one each) (Avonce et al. 2010). The S. lepidophylla EST library (Iturriaga et al. 2006) screening resulted in the isolation of a putative SITPS class II fragment. Based on this fragment, specific primers were designed (supplementary Table 1), and the SITPS class II cDNA clone was amplified. This class II enzyme had 849 amino acids and, similar to the class II proteins of other plants, could not complement yeast tps 1 or tps 2 mutants (data not shown). Phylogenetic analysis with homologous
TPS class II genes from A. thaliana, P. patens, and $S$. moellendorffii (Fig. 3a) indicated that the closest homolog for SITPS class II was the TPS class II SM0003G06280 gene from $S$. moellendorffii ( $88.9 \%$ identity). The second TPS class II gene from S. moellendorffii, SM0057G00180, had $71.84 \%$ identity with our SITPS class II gene. Shared identity with the four $P$. patens TPS II genes was 73.37 , 74.46, 69.14 and $70.93 \%$ for PP0081G00980, PP00088900870, PP00080G00530, and PP00153G00600, respectively. Among the seven AtTPS class II genes, SITPS class II shared closest homology with AtTPS5 $(67.78 \%$ identity, AT4G17770). Because the whole genome sequence is not yet available, how many class II enzymes there are in S. lepidophylla is not clear.

Relative transcript levels of SITPSI, SITPPA, and $S I T P P B$ during hydrated and dehydrated states of S. lepidophylla

The expression levels of three trehalose biosynthetic genes were measured. The expression level of SITPSI did not change significantly between the hydrated and dehydrated states of S. lepidophylla (Fig. 4). In the case of the TPP genes, SITPPA expression was significantly decreased during dehydration, while there was no significant difference in the expression level of SITPPB between the two states. As mentioned above, trehalose levels do not differ significantly between the hydrated and dehydrated states of this species (Adams et al. 1990; Yobi et al. 2013).

\section{Discussion}

The high trehalose levels in S. lepidophylla have always been linked to its high drought-stress tolerance. One of the first genes isolated from this plant was SITPS1, encoding a trehalose-6-phosphate synthase (Zentella et al. 1999). However, heterologous expression in yeast showed that this enzyme was even less active than AtTPS1 (Van Dijck et al. 2002). If trehalose biosynthesis was linked to drought-stress tolerance, one would expect the enzymatic activity and trehalose levels to be higher in the dry state. However, SITPS1 is active in both the dry and hydrated states, with fully-hydrated plants having the highest SITPS1 activity (Márquez-Escalante et al. 2006). Additionally, the levels of trehalose were not significantly different between the dry and hydrated states. The level of trehalose in S. lepidophylla corresponded to the levels measured in microbes, which are 3,000 times higher than in plants such as rice, tomato, and potato. Although high trehalose levels have been linked specifically with the desiccation-tolerance of $S$. lepidophylla, a large-scale comparative metabolomics study revealed that $S$. moellendorffii, the 
Fig. 3 Phylogenetic analysis of an SITPS class II gene. A full-length TPS class II gene of Selaginella lepidophylla was isolated. Phylogenetic analysis shows that it shares most homology with a class II enzyme of $S$. moellendorffii

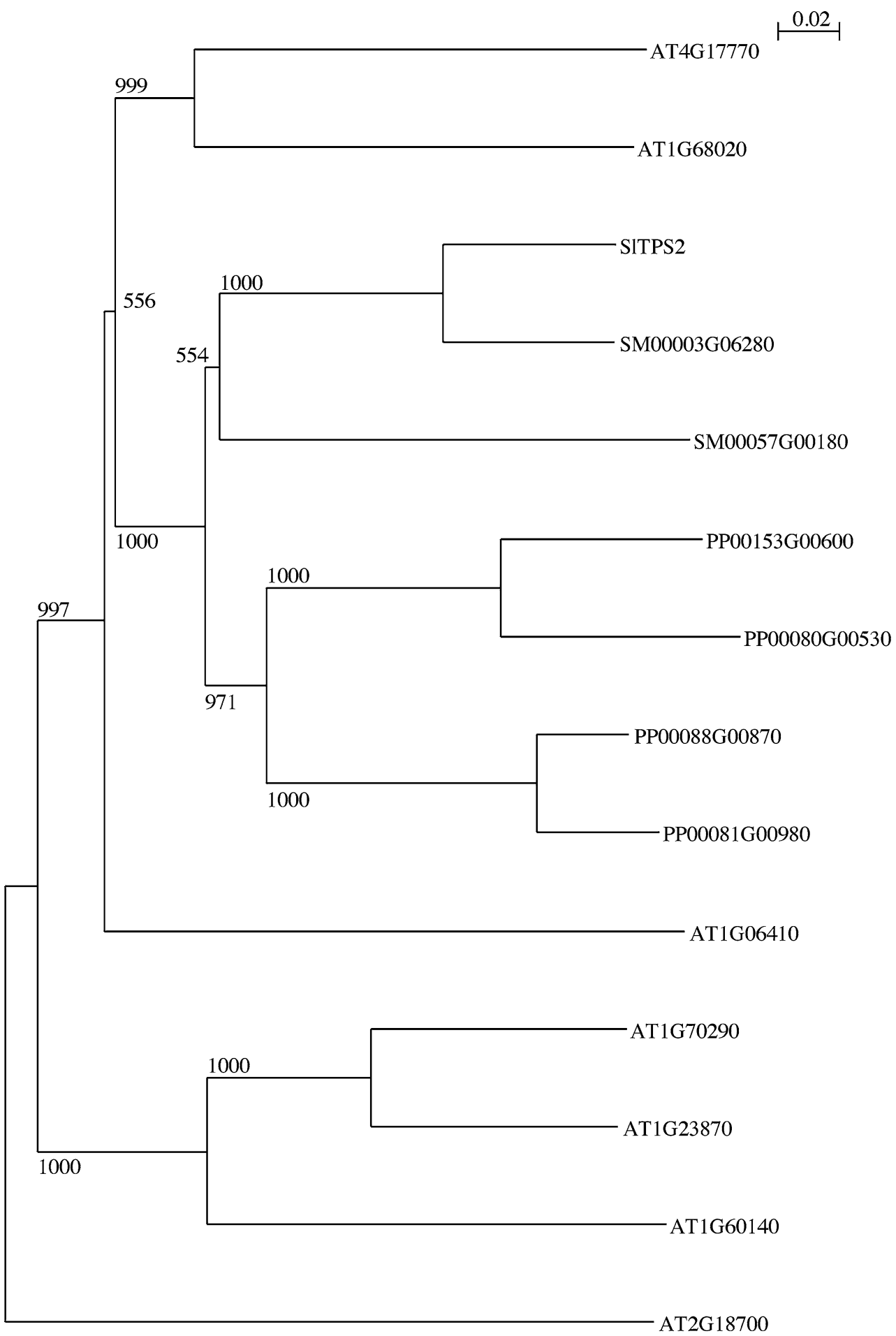

drought-sensitive relative of $S$. lepidophylla, had even higher levels of trehalose than S. lepidophylla (Yobi et al. 2012). The high trehalose levels detected in both lycophytes represent an evolutionary-preserved metabolic feature that requires further study. The results obtained here question the origin of trehalose in S. lepidophylla, because the S. lepidophylla cDNA library screenings resulted in the isolation of
T6P synthases of microbial origin (Table 1; Fig. 1a, b). This finding may explain the similar trehalose concentrations in the hydrated and dry states. Furthermore, ultrastructural analysis of $S$. lepidophylla during rehydration clearly showed the presence of fungi and bacteria in the dry microphylls (Brighigna et al. 2002). These facts, together with the isolation of TPS genes of microbial origin and the 


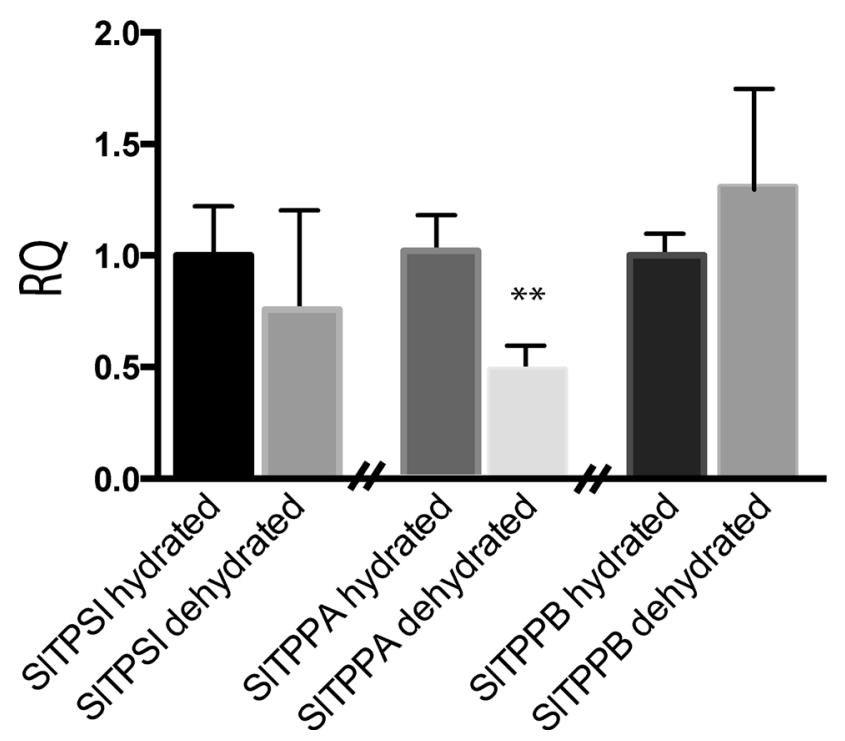

Fig. 4 Relative transcript levels of SITPS1, SITPPA, and SITPPB in the hydrated and dehydrated states of Selaginella lepidophylla. SITPPA relative transcript levels are significantly lower in the dehydrated state $(P<0.01$; Student's $t$ test, $n=9)$. There is no significant difference in the expression levels of SITPS1 and SITPPB in the two states

absence of expression differences in S. lepidophylla TPS and $T P P$ genes strongly support the hypothesis that trehalose in this plant is of microbial origin. Recently, the S. moellendorffii genome was shown to also contain DNA from nucleocytoplasmic large DNA viruses, probably a result of horizontal gene transfer (Maumus et al. 2014). The endogenous origin of trehalose in S. lepidophylla could be proven by measuring trehalose content in sterile in vitro cultures of the plant. However, attempts to grow S. lepidophylla in vitro from spores have failed, probably because of the lack of symbiotic bacteria/fungi necessary for this lycophyte to grow (G. Iturriaga, personal communication), further supporting the microbial origin of trehalose production.

As the cDNA library screening was not successful in isolating SITPP genes, degenerate-oligonucleotide PCR approaches were used to isolate three SITPP genes (SITPPA, SITPPB and SITPPC) from the cDNA library. The phylogenetic analysis showed that SITPPA and SITPPC were orthologs of two $S$. moellendorffii genes, suggesting common ancestor genes prior to speciation, while SITPPB did not appear to have an ortholog in $S$. moellendorffi (Fig. 2a). The complementation of the yeast tps $2 \Delta$ mutant and enzymatic activity determinations proved that both SITPPA and SITPPB were active TPP proteins, although their activity (nkat $g$ protein ${ }^{-1}$ ) values were very low compared with that of ScTPS2 (WT control) and slightly higher than that of the tps $2 \triangle$ strain (the negative control) (Table 2) (SITPPC was not tested in this assay). The low enzymatic activity of the SITPP enzymes did not differ significantly from that of AtTPPB, which was used as a control (Fig. 2b; Table 2). Again, the data indicate that the basic enzymatic activity of TPP in S. lepidophylla did not differ from that of other plants, so it probably cannot account for the higher presence of trehalose.

Finally, similar to all other plant species, S. lepidophylla has at least one class II enzyme, which we isolated using a PCR approach. This means that all three groups of enzymes (or regulatory proteins in the case of the class II protein) are present in this resurrection plant. Sequencing of the $S$. lepidophylla genome would provide an opportunity to characterize the complete trehalose biosynthetic gene family in this desiccation-tolerant plant. In the case of S. moellendorffii, in silico evolutionary studies of the gene family are possible, because its genome has already been sequenced (Banks et al. 2011), and in silico studies of other gene families have already been performed (Saha et al. 2013). Evolutionary studies of the S. lepidophylla trehalose biosynthetic genes might provide important hints into their specific functions under different conditions. Our expression analysis already suggests diverse regulation of SITPPA and SITPPB during hydration and dehydration. SITPPA transcript levels were significantly lower during dehydration, while the expression of SITPPB did not change significantly during this process.

The fact that $S$. moellendorffii has similarly high trehalose levels to S. lepidophylla but is drought-stress sensitive seems to suggest that other characteristics (maybe together with trehalose) are involved in the latter's desiccation tolerance. An overview of these characteristics can be found in the review by Pampurova and Van Dijck (2014).

\section{Conclusions}

The isolation and characterization of three SITPPs genes and one SITPS class II gene, together with the previously characterized SITPS1, showed that this plant also has all three groups of trehalose biosynthesis enzymes. The most striking result of our work was the isolation of many TPS genes of microbial origin from our cDNA library. Additionally, the S. lepidophylla TPPA and TPPB enzymes were not more active than A. thaliana TPPB. Taken together, the results suggest that the high trehalose content in this plant (and probably also in S. moellendorffii) is of microbial origin.

Acknowledgments We would like to thank Prof. G. Iturriaga for providing us with S. lepidophylla plants and Nico Vangoethem for help with the figures. This work was supported by doctoral grants from the Research Council of the KU Leuven to SP, and the IWT to $\mathrm{KV}$ and by the Fund for Scientific Research Flanders (FWO; G.0859.10). 


\section{References}

Adams RP, Kendall E, Kartha KK (1990) Comparison of free sugars in growing and desiccated plants of Selaginella lepidophylla. Biochem Syst Ecol 18:107-110

Avonce N, Mendoza-Vargas A, Morett E, Iturriaga G (2006) Insights on the evolution of trehalose biosynthesis. BMC Evol Biol 6:109

Avonce N, Wuyts J, Verschooten K, Vandesteene L, Van Dijck P (2010) The Cytophaga hutchinsonii ChTPSP: first characterized bifunctional TPS-TPP protein as putative ancestor of all eukaryotic trehalose biosynthesis proteins. Mol Biol Evol 27:359-369

Banks JA, Nishiyama T, Hasebe M, Bowman JL, Gribskov M, dePamphilis C, Albert VA, Aono N, Aoyama T, Ambrose BA, Ashton NW, Axtell MJ, Barker E, Barker MS, Bennetzen JL, Bonawitz ND, Chapple C, Cheng C, Correa LG, Dacre M, DeBarry J, Dreyer I, Elias M, Engstrom EM, Estelle M, Feng L, Finet C, Floyd SK, Frommer WB, Fujita T, Gramzow L, Gutensohn M, Harholt J, Hattori M, Heyl A, Hirai T, Hiwatashi Y, Ishikawa M, Iwata M, Karol KG, Koehler B, Kolukisaoglu U, Kubo M, Kurata T, Lalonde S, Li K, Li Y, Litt A, Lyons E, Manning G, Maruyama T, Michael TP, Mikami K, Miyazaki S, Morinaga S, Murata T, Mueller-Roeber B, Nelson DR, Obara M, Oguri Y, Olmstead RG, Onodera N, Petersen BL, Pils B, Prigge M, Rensing SA, Riano-Pachon DM, Roberts AW, Sato Y, Scheller HV, Schulz B, Schulz C, Shakirov EV, Shibagaki N, Shinohara N, Shippen DE, Sorensen I, Sotooka R, Sugimoto N, Sugita M, Sumikawa N, Tanurdzic M, Theissen G, Ulvskov P, Wakazuki S, Weng JK, Willats WW, Wipf D, Wolf PG, Yang L, Zimmer AD, Zhu Q, Mitros T, Hellsten U, Loque D, Otillar R, Salamov A, Schmutz J, Shapiro H, Lindquist E, Lucas S, Rokhsar D, Grigoriev IV (2011) The Selaginella genome identifies genetic changes associated with the evolution of vascular plants. Science 332:960-963

Becker A, Schlöder P, Steele JE, Wegener G (1996) The regulation of trehalose metabolism in insects. Experientia 52:433-439

Bergtrom G, Schaller M, Eickmeier WG (1982) Ultrastructural and biochemical bases of resurrection in the drought-tolerant vascular plant, Selaginella lepidophylla. J Ultrastruct Res 78:269-282

Bonini BM, Van Dijck P, Thevelein JM (2003) Uncoupling of the glucose growth defect and the deregulation of glycolysis in Saccharomyces cerevisiae Tps1 mutants expressing trehalose-6phosphate-insensitive hexokinase from Schizosaccharomyces pombe. Biochim Biophys Acta 1606:83-93

Bradford MM (1976) A rapid and sensitive method for the quantitation of microgram quantities of protein utilizing the principle of protein-dye binding. Anal Biochem 72:248-254

Brighigna L, Bennici A, Tani C, Tani G (2002) Structural and ultrastructural characterization of Selaginella lepidophylla, a desiccation-tolerant plant, during the rehydration process. Flora 197:81-91

Crowe JH (2007) Trehalose as a "chemical chaperone": fact and fantasy. Adv Exp Med Biol 594:143-158

Crowe JH, Hoekstra FA, Crowe LM (1992) Anhydrobiosis. Annu Rev Physiol 54:579-599

De Virgilio C, Bürckert N, Bell W, Jenö P, Boller T, Wiemken A (1993) Disruption of TPS2, the gene encoding the 100-kDa subunit of the trehalose-6-phosphate synthase/phosphatase complex in Saccharomyces cerevisiae, causes accumulation of trehalose-6-phosphate and loss of trehalose-6-phosphate phosphatase activity. Eur J Biochem 212:315-323

Elbein AD, Pan YT, Pastuszak I, Carroll D (2003) New insights on trehalose: a multifunctional molecule. Glycobiology 13:17R-27R

Elble R (1992) A simple and efficient procedure for transformation of yeasts. Biotechniques 13:18-20
Gietz RD, Schliestl RH, Willems AR, Woods RA (1995) Studies on the transformation of intact yeast cells by the LiAc/SS-DNA/ PEG procedure. Yeast 11:355-360

Hengherr S, Heyer AG, Köhler HR, Schill RO (2008) Trehalose and anhydrobiosis in tardigrades-evidence for divergence in responses to dehydration. FEBS J 275:281-288

Hohmann S, Neves MJ, de Koning W, Alijo R, Ramos J, Thevelein JM (1993) The growth and signalling defects of the ggsl (fdpl/ byp1) deletion mutant on glucose are suppressed by a deletion of the gene encoding hexokinase PII. Curr Genet 23:281-289

Hohmann S, Bell W, Neves MJ, Valckx D, Thevelein JM (1996) Evidence for trehalose-6-phosphate-dependent and -independent mechanisms in the control of sugar influx into yeast glycolysis. Mol Microbiol 20:981-991

Iturriaga G, Cushman MAF, Cushman JC (2006) An EST catalogue from the resurrection plant Selaginella lepidophylla reveals abiotic stress-adaptive genes. Plant Sci Int J Exp Plant Biol 170:1173-1184

Larkin MA, Blackshields G, Brown NP, Chenna R, McGettigan PA, McWilliam H, Valentin F, Wallace IM, Wilm A, Lopez R, Thompson JD, Gibson TJ, Higgins DG (2007) Clustal W and Clustal X version 2.0. Bioinformatics 23:2947-2948

Lederer E (1976) Cord factor and related trehalose esters. Chem Phys Lipids 16:91-106

Leyman B, Van Dijck P, Thevelein JM (2001) An unexpected plethora of trehalose biosynthesis genes in Arabidopsis thaliana. Trends Plant Sci 6:510-513

Lunn JE (2007) Gene families and evolution of trehalose metabolism in plants. Funct Plant Biol 34:550-563

Márquez-Escalante JA, Figueroa-Soto CG, Valenzuela-Soto EM (2006) Isolation and partial characterization of trehalose-6phosphate synthase aggregates from Selaginella lepidophylla plants. Biochimie 88:1505-1510

Maumus F, Epert A, Nogué F, Blanc G (2014) Plant genomes enclose footprints of past infections by giant virus relatives. Nat Commun 5:4268

Müller J, Boller T, Wiemken A (1995) Trehalose and trehalase in plants: recent developments. Plant Sci 112:1-9

Neves MJ, Hohmann S, Bell W, Dumortier F, Luyten K, Ramos J, Cobbaert P, Dekoning W, Kaneva Z, Thevelein JM (1995) Control of glucose influx into glycolysis and pleiotropic effects studied in different isogenic sets of Saccharomyces cerevisiae mutants in trehalose biosynthesis. Curr Genet 27:110-122

Oliver MJ, Tuba Z, Mishler BD (2000) The evolution of vegetative desiccation tolerance in land plants. Plant Ecol 151:85-100

Pampurova S, Van Dijck P (2014) The desiccation tolerant secrets of Selaginella lepidophylla: what we have learned so far? Plant Physiol Biochem 80:285-290

Perrière G, Gouy M (1996) WWW-query: an on-line retrieval system for biological sequence banks. Biochimie 78:364-369

Proost S, Van Bel M, Sterck L, Billiau K, Van Parys T, Van de Peer Y, Vandepoele K (2009) PLAZA: a comparative genomics resource to study gene and genome evolution in plants. Plant Cell 21:3718-3731

Saha J, Gupta K, Gupta B (2013) In silico characterization and evolutionary analyses of CCAAT binding proteins in the lycophyte plant Selaginella moellendorffii genome: a growing comparative genomics resource. Comput Biol Chem 47:81-88

Sievers F, Wilm A, Dineen D, Gibson TJ, Karplus K, Li W, Lopez R, McWilliam H, Remmert M, Soding J, Thompson JD, Higgins DG (2011) Fast, scalable generation of high-quality protein multiple sequence alignments using Clustal Omega. Mol Syst Biol 7:539

Thevelein JM (1984) Regulation of trehalose mobilization in fungi. Microbiol Rev 48:42-59 
Thomas BJ, Rothstein RJ (1989) Elevated recombination rates in transcriptionally active DNA. Cell 56:619-630

Valenzuela-Avendano JP, Estrada Mota IA, Lizama G, Souza Perera R, Valenzuela-Soto EM, Zuniga Aguilar JJ (2005) Use of a simple method to isolate intact RNA from partially hydrated Selaginella lepidophylla plants. Plant Mol Biol Rep 23:199a$199 \mathrm{~g}$

Valenzuela-Soto EM, Márquez-Escalante JA, Iturriaga G, FigueroaSoto CG (2004) Trehalose 6-phosphate synthase from Selaginella lepidophylla: purification and properties. Biochem Biophys Res Commun 313:314-319

Van Dijck P, Mascorro-Gallardo JO, De Bus M, Royackers K, Iturriaga G, Thevelein JM (2002) Truncation of Arabidopsis thaliana and Selaginella lepidophylla trehalose-6-phosphate synthase (TPS) unlocks high catalytic activity and supports high trehalose levels upon expression in yeast. Biochem J 366:63-71

Van Mullem V, Wery M, De Bolle X, Vandenhaute J (2003) Construction of a set of Saccharomyces cerevisiae vectors designed for recombinational cloning. Yeast 20:739-746

Yobi A, Wone BW, Xu W, Alexander DC, Guo L, Ryals JA, Oliver MJ, Cushman JC (2012) Comparative metabolic profiling between desiccation-sensitive and desiccation-tolerant species of Selaginella reveals insights into the resurrection trait. Plant J 72:983-999

Yobi A, Wone BW, Xu W, Alexander DC, Guo L, Ryals JA, Oliver MJ, Cushman JC (2013) Metabolomic profiling in Selaginella lepidophylla at various hydration states provides new insights into the mechanistic basis of desiccation tolerance. Mol Plant 6:369-385

Zaparty M, Hagemann A, Bräsen C, Hensel R, Lupas AN, Brinkmann H, Siebers B (2013) The first prokaryotic trehalose synthase complex identified in the hyperthermophilic crenarchaeon Thermoproteus tenax. PLoS ONE 8:e61354

Zentella R, Mascorro-Gallardo JO, Van Dijck P, Folch-Mallol J, Bonini B, Van Vaeck C, Gaxiola R, Covarrubias AA, NietoSotelo J, Thevelein JM, Iturriaga G (1999) A Selaginella lepidophylla trehalose-6-phosphate synthase complements growth and stress-tolerance defects in a yeast tps 1 mutant. Plant Physiol 119:1473-1482 